\title{
Valoració de la condició física en educació infantil: orientacions per a l'aplicació a l'aula
}

\author{
Diego Moliner Urdiales (dmoliner@uji.es), Óscar Chiva Bartoll \\ (ochiva@uji.es),María Reyes Beltrán Valls (vallsm@uji.es)
}

\section{Condició física}

La condició física fa referència a la capacitat d'un individu per a realitzar una activitat física, i pot analitzar-se des de la perspectiva del rendiment esportiu o des de la salut. Es tracta d'un estat dinàmic determinat genèticament però que pot ser modificat per factors ambientals, com ara la pràctica d'exercici físic. La condició física relacionada amb la salut fa referència a l'habilitat de dur a terme les activitats de la vida diària amb vigor, així com a les característiques i capacitats que estan associades amb un baix risc de desenvolupar malalties cròniques i mort prematura (Ruiz i altres, 2009).

Tot i que hi ha diferents classificacions respecte d'això, pareix àmpliament reconegut en l'àmbit científic que els principals components de la condició física relacionada amb la salut són la resistència aeròbica, la força muscular, l'aptitud motriu i la composició corporal (Ruiz i altres, 2009). La valoració d'aquestes capacitats reflecteix l'estat funcional dels diferents òrgans i sistemes involucrats majoritàriament en l'activitat física realitzada.

La resistència cardiorespiratòria, també denominada resistència aeròbica, fa referència a la capacitat total dels sistemes cardiovascular i respiratori, així com a l'habilitat de l'organisme per a mantenir un exercici extenuant de forma prolongada en el temps (Taylor, Buskirk i Henschel, 1955). Aquesta capacitat de resistència constitueix una mesura directa de l'estat general de salut, i de manera específica de l'estat dels sistemes cardiorespiratori i metabòlic. Hi ha fortes evidències científiques que posen de manifest el seu efecte protector sobre el sistema cardiovascular des d'edats primerenques (Ortega, Ruiz, Castillo i Sjöström, 2008).

La força muscular constitueix la capacitat per a realitzar un treball en contra d'una resistència, i s'ha d'entendre com una capacitat molt àmplia condicionada per nombrosos factors, entre els quals destaquen el tipus de treball, la grandària i el nombre de músculs implicats, el percentatge de fibres musculars implicades, la capacitat de coordinació inter i intramuscular i la mobilitat articular. Els principals components de la força muscular relacionada amb la salut són la força màxima, la força explosiva i la força resistència. Actualment hi ha fortes evidències científiques que associen la força muscular amb diferents indicadors de salut ja des de les primeres edats (Ruiz i altres, 2008), que passa a considerarse un important indicador de l'estat de salut actual i un bon predictor de l'estat de salut futura (Ortega i altres, 2008).

L'aptitud motriu inclou els components de la condició física relacionats amb les habilitats motrius, dels quals els seus principals components són la velocitat, l'agilitat i l'equilibri (Caspersen, Powell i Christenson, 1985). La literatura científica mostra certes 
evidències que relacionen l'aptitud motriu amb l'estat de salut i el rendiment acadèmic en xiquets.

La composició corporal fa referència a la distribució dels principals teixits que componen el cos humà; és a dir, la massa òssia, la massa magra i la massa greixosa. L'obesitat es defineix com una acumulació excessiva de teixit gras, i actualment és considerada una epidèmia global amb gravíssims efectes sobre la salut des de les primeres edats (Cattaneo i altres, 2010; de Onis, Blossner i Borghi, 2010).

\section{Importància de la condició física}

Actualment hi ha suficient evidència científica per a ratificar la importància de mantenir nivells òptims de condició física al llarg de tota la vida per a mantenir-se mentalment, metabòlicament, físicament i funcionalment saludables (Ruiz i altres, 2009). És per això que es considera que la condició física és un poderós indicador de salut a qualsevol edat. No obstant això, recents estudis mostren que els nivells mitjans de condició física a Espanya estan per davall del que seria desitjable (Gulías-González i altres, 2014).

L'estil de vida actual dels xiquets i adolescents fa que s'haja reduït el temps de pràctica d'activitats físiques i esportives, amb una major presència d'activitats d'oci sedentari enfront d'una pantalla (Cooper i altres, 2015; Tucker, 2008). Aquests canvis de comportament impliquen una notable reducció de la despesa energètica diària, la qual cosa permet explicar en part l'augment de l'obesitat infantil i l'increment exponencial de nombrosos factors de risc de malalties que s'hi relacionen (Liria, 2012; Rey-López i altres, 2008). Són nombrosos els estudis que han identificat una relació inversa entre la condició física i el percentatge de greix corporal (Moliner-Urdiales i altres, 2011; Ortega i altres, 2007) o malalties cròniques (Artero i altres, 2011). Per això, la valoració i el desenvolupament de la condició física poden constituir una eina útil per a combatre l'obesitat infantil i els factors de risc que s'hi associen.

L'activitat física regular està positivament associada amb la millora de la condició física, per la qual cosa la seua valoració dins del context de l'educació infantil és fonamental per a determinar l'efectivitat o la necessitat d'articular estratègies de promoció d'activitat física saludable en la infància (Ward i altres, 2010). El coneixement del nivell inicial de condició física pot ser útil per a verificar el progrés de cada xiquet en resposta a programes específics d'activitat física, així com per a adaptar aquests programes en funció de les carències específiques de l'alumnat. Així mateix, és important conèixer el nivell en què cada xiquet $^{1} \mathrm{o}$ grup de xiquets es troba respecte a valors mitjans o recomanats per a poder identificar necessitats específiques en cada un.

D’aquesta manera, la valoració de la condició física pot ser vista com una eina educativa que motive a establir situacions pedagògiques per a millorar-la i amb això optimitzar l'estat de salut de l'alumnat (Ardoy i altres, 2011). Transmetre als pares el registre i l'evolució dels xiquets en cada component de la condició física pot ser un aspecte més que motive les famílies a la realització d'activitat física de diferents modalitats regularment com a hàbit saludable.

\footnotetext{
${ }^{1}$ Per motius de claredat i fluïdesa expositiva hem optat per l'ús del masculí com a genèric.
} 


\section{Valoració de la condició física}

Basant-se en la definició prèviament establida per a la condició física relacionada amb la salut, la seua valoració hauria de comprendre l'avaluació dels diferents components que la integren: la resistència cardiorespiratòria, la força muscular, l'aptitud motriu i la composició corporal. La valoració de la condició física pot dur-se a terme dins o fora d'un laboratori. Malgrat que les proves o test de laboratori són considerats com els instruments de valoració més precisos, vàlids i fiables, el seu ús comporta un elevat cost econòmic i l'aplicació de tècniques sofisticades que habitualment requereixen personal altament qualificat. Els test realitzats fora del laboratori, també coneguts com test de camp, constitueixen una alternativa barata, senzilla i que al mateix temps permet obtenir dades amb nivells acceptables de precisió, validesa i fiabilitat. La seua aplicació en grans estudis epidemiològics és molt habitual, i constitueix una eina àmpliament acceptada per la comunitat científica.

La gran varietat de test de camp que permeten avaluar la condició física en xiquets i adolescents genera un problema per als professionals de l'educació física i de l'esport a l'hora de decidir quin test és més apropiat. En una excel-lent revisió sistemàtica duta a terme per Castro-Pinero i altres, (2010) es posen de manifest les limitacions i la falta d'evidències científiques que avalen l'aplicació de molts d'aquests. De fet, els autors només van trobar evidències robustes sobre la validesa de l'ús del test de $20 \mathrm{~m}$ d'anada i tornada (course navette) per a avaluar la resistència aeròbica, del test de prensió manual per a avaluar la força muscular, i del mesurament dels plecs cutanis i de l'índex de massa corporal per a estimar la composició corporal. Basant-se en aquests antecedents, i fruit de l'intens treball d'un grup multidisciplinari format per investigadors de diferents països europeus, l'any 2011 es va publicar la bateria ALPHA (Assessing Levels of Physical Activity and Fitness). $S$ 'hi proposen una sèrie de test vàlids i fiables per a avaluar la condició física relacionada amb la salut en xiquets i joves des dels 6 fins als 18 anys (Ruiz i altres, 2011).

Tenint en compte els antecedents previs, resulta evident que la condició física ha de ser avaluada de forma precisa des dels primers anys de vida per a comprendre'n la relació amb la salut, així com per a tractar de quantificar els efectes que té sobre l'estat de salut actual i futur (Berenson i altres, 1998). Pareix raonable pensar que una baixa condició física durant els primers anys de vida pot comportar un increment del risc de morbiditat $i$ mortalitat en el futur. Per tant, la valoració de la condició física s'ha convertit en un element clau des del punt de vista clínic i de salut pública. Encara que moltes de les patologies que apareixen en l'edat adulta estan associades amb la condició física durant els primers anys de vida, la majoria de les bateries de condició física adaptades a xiquets solen recomanarne l'aplicació a partir dels 6 anys (Castro-Pinero i altres, 2010).

\section{Valoració de la condició física en la infància}

El nivell de desenvolupament tant físic com cognitiu dels xiquets menors de 3 anys fa molt difícil poder avaluar de forma adequada la seua condició física en el primer cicle d'educació infantil (0-3 anys). Però el segon cicle d'educació infantil a Espanya (3-6 anys) constitueix una oportunitat única per a realitzar un seguiment sistemàtic de l'evolució de 
la condició física relacionada amb la salut (Ayán Pérez, 2013). No obstant això, qüestions com la dificultat per a triar test de camp que avaluen amb garanties la condició física, la carència de formació específica del professorat o l'absència de valors de referència, entre altres dificultats, han provocat que la valoració de la condició física en educació infantil no s'haja desplegat en profunditat en el marc escolar.

Diferents propostes de test de condició física relacionada amb la salut per a xiquets menors de 6 anys han mostrat escasses evidències científiques sobre la seua precisió, validesa i fiabilitat. Gràcies a una recent revisió sistemàtica de la literatura científica actual (Ortega i altres, 2015), és possible afirmar que els test amb major aval científic són el test de $20 \mathrm{~m}$ d'anada i tornada, el test de la mitja milla, el test dels tres minuts, el test de prensió manual i el test de $4 \times 10 \mathrm{~m}$. L'esmentada revisió ha constituït el punt de partida per a la confecció d'una bateria de test de condició física relacionada amb la salut adaptada a xiquets amb edats compreses entre els 3 i els 5 anys.

Basats en aquestes evidències científiques, i gràcies a un projecte multicèntric d'àmbit nacional liderat des de la Universitat de Granada i en el qual el nostre grup d'investigació LIFE de la Universitat Jaume I està colllaborant, s'ha proposat recentment la bateria PREFIT (http://profith.ugr.es/recursos-prefit) com un instrument adequat per a avaluar la condició física relacionada amb la salut en xiquets de 3 a 5 anys (Cadenas-Sanchez i altres, 2016).

La bateria PREFIT compren l'avaluació de la composició corporal, la força muscular, l'aptitud motriu i la resistència cardiorespiratòria a través d'una sèrie de test senzills que han demostrat òptims nivells de validesa i de fiabilitat, a més de comptar amb evidències científiques que els relacionen directament amb l'estat de salut actual i futura del xiquet.

- Composició corporal: índex de massa corporal i perímetre de cintura.

- Força muscular: test de prensió manual i salt de longitud.

- Aptitud motriu: test de 4 x $10 \mathrm{~m}$ i test d'equilibri monopodal.

- Resistència cardiorespiratòria: test de $20 \mathrm{~m}$ d'anada i tornada (course navette adaptada).

Quan s'apliquen test per a la valoració de la condició física, és important tenir en compte l'edat dels participants, ja que aquesta determinarà la metodologia utilitzada per a la seua aplicació. El currículum vigent d'aquesta etapa (Llei Orgànica d'Educació 2/2006, de 3 de maig) proposa un enfocament globalitzador de la psicomotricitat en el qual la valoració de la condició física té ple sentit. En aquest context, és raonable apostar per mètodes de treball basats en experiències, activitats i jocs aplicats en ambients d'afecte i de confiança (LOE, art. 14.6); la qual cosa es tradueix en l'ús de recursos metodològics com les cançons, els contes motors i els circuits motors.

En aquesta línia, utilitzar un conte motor constitueix un recurs didàctic que actua com a element motivador per a l'alumnat i que, al seu torn, permet introduir de manera lúdica els distints test de condició física. Seguint Ruiz Omeñaca (2011), el conte motor es defineix com una narració breu, amb un fil argumental senzill, que remet a un escenari imaginari en què els personatges actuen en un context de repte i aventura. Del relat naixen propostes en què l'alumnat participa activament representant diferents personatges que han d'anar superant proves, en aquest cas, els distints test de condició física de la bateria, com si d'una actuació teatral o de la vivència d'una emocionant aventura es tractara.

Una altra aposta metodològica per a incorporar la valoració de la condició física en les aules d'infantil pot materialitzar-se en l'aprenentatge per projectes, també referit per alguns 
autors com projectes de treball. Des d'aquest enfocament, l'aprenentatge sorgiria de l'interès i curiositat de l'alumnat sobre un tema concret o situació problemàtica (Maravé i altres, 2016). En aquest cas, el projecte podria construir-se al voltant de la temàtica de la salut $i$ els estils de vida saludables. Després de l'elecció del tema, en una fase inicial d'activació de coneixements previs, el grup abordaria continguts curriculars bàsics vinculats amb la condició física orientada a la salut, així com amb hàbits saludables d'alimentació i d'higiene. Posteriorment, en la fase d'activitats de desenvolupament, podrien dedicar-se algunes sessions al tractament dels principals components de la condició física orientada a la salut, així com les seues possibilitats de millora en relació amb determinats estils de vida i d'alimentació. Aquest plantejament podria reforçar-se i complementar-se amb estratègies com ara imitar situacions de la vida real en què els alumnes pogueren identificar-se; o visualitzar i identificar imatges digitals relatives a distints hàbits saludables i reflexionar sobre les seues possibles conseqüències. Aquest escenari pedagògic permetria incorporar, d'una manera lúdica i contextualitzada, l'aplicació de diferents test específics de condició física.

Aquestes possibilitats metodològiques estan en línia amb les propostes legislatives dedicades al segon cicle d'educació infantil, en les quals es presumeix la necessitat d'un enfocament global, capaç d'integrar el desenvolupament i l'avaluació de la condició física amb la resta de manifestacions motrius. Un dels objectius principals del cicle en aquest àmbit al·ludeix a conèixer el propi cos i el dels altres, així com les seues possibilitats d'acció, tot aprenent a respectar-hi les diferències. Aquest vessant del currículum se substancia específicament en una de les tres àrees de coneixement que el vertebren, la referida al «Coneixement de si mateix i autonomia personal». Aquesta àrea es marca com a horitzó que l'alumnat siga capaç d'identificar les característiques i les capacitats físiques i motrius pròpies i les dels altres, i s'estableixen actituds que afavoresquen la salut i l'atenció d'un mateix. Per tant, de l'avaluació de la condició física se'n deriva un valor educatiu en si mateix.

La valoració de la condició física per a la salut en l'etapa d'educació infantil adquireix el seu màxim sentit en transferir la informació als familiars a través d'informes individuals. De fet, el currículum educatiu fa especial menció de la importància de comunicar periòdicament a les famílies la informació relativa a les capacitats dels xiquets, ja que conèixer els distints estats d'evolució permetrà ajustar els processos educatius a la diversitat de l'alumnat. D'altra banda, els resultats de valoració de la condició física poden ser també d'interès per als pediatres, ja que els facilitaria, en aquest àmbit, una valoració objectiva de l'estat de salut dels xiquets. Finalment, la transmissió dels resultats directament a l'alumnat podria ser d'interès perquè aquests prengueren consciència del seu estat. En aquest sentit, la fórmula de transmissió dels resultats hauria d'evitar comparacions entre companys, centrant-se específicament a conèixer les pròpies capacitats i limitacions, així com les seues possibilitats de millora.

\section{Conclusions}

La valoració de la condició física relacionada amb la salut en educació infantil és una iniciativa factible mitjançant l'aplicació de bateries de test vàlides i adaptades pedagògicament a les característiques de l'alumnat. Amb això es pot complementar 
el treball de desenvolupament motor en aquestes edats, tot proporcionant informació estandarditzada de l'evolució de la condició física i promoure la necessitat de millorar-la a través de la pràctica regular d'activitat física. En definitiva, resulta una eina educativa per a la promoció d'hàbits saludables, amb gran repercussió des del punt de vista de la salut pública per la seua importància per al benestar físic actual i futur.

\section{BIBLIOGRAFIA}

Ardoy, D.N., Fernández-Rodríguez, J.M., Ruiz, J.R. i altres (2011): «Mejora de la condición física en adolescentes a través de un programa de intervención educativa: Estudio EDUFIT», Revista Española de Cardiología, 64(6), 484-491.

Artero, E.G., Ruiz, J.R., Ortega, F.B., España-Romero, V. i altres (2011): «Muscular and cardiorespiratory fitness are independently associated with metabolic risk in adolescents: the HELENA study», Pediatric Diabetes, 12(8), 704-712.

Ayán PÉrez, C. (2013): «Valoración de la condición física en el contexto de la educación infantil: aplicaciones prácticas», Apunts. Educación Física Y Deportes, 112, 52-62.

Berenson, G. S., SRinivasan, S. R., Bao, W. i altres (1998): «Association between Multiple Cardiovascular Risk Factors and Atherosclerosis in Children and Young Adults», New England Journal of Medicine, 338(23), 1650-1656.

Cadenas-Sanchez, C., Martinez-Tellez, B., Sanchez-Delgado, G., i altres (2016): «Assessing physical fitness in preschool children: Feasibility, reliability and practical recommendations for the PREFIT battery», Journal of Science and Medicine in Sport, 19(11), 910-915.

Caspersen, C.J., Powell, K.E. i G.M. Christenson (1985): «Physical activity, exercise, and physical fitness: definitions and distinctions for health-related research», Public Health Reports, 100(2), 126-131.

Castro-Pinero, J., Artero, E.G., Espana-Romero, V. i altres (2010): «Criterion-related validity of field-based fitness tests in youth: a systematic review», British Journal of Sports Medicine, 44(13), 934-943.

Cattaneo, A., Monasta, L., Stamatakis, E., Lioret, S. i altres (2010): «Overweight and obesity in infants and pre-school children in the European Union: a review of existing data», Obesity Reviews, 11(5), 389-98.

CoOPER, A.R., Goodman, A. i altres (2015): «Objectively measured physical activity and sedentary time in youth: the International children's accelerometry database (ICAD)», International Journal of Behavioral Nutrition and Physical Activity, 12(1), 113.

de Onis, M., Blossner, M. i E. Borghi (2010): «Global prevalence and trends of overweight and obesity among preschool children», American Journal of Clinical Nutrition, 92(5), 1257-1264.

Gulías-GonzÁlez, R., Sánchez-López, M., Olivas-Bravo, Á., Solera-Martínez i altres (2014): «Physical Fitness in Spanish Schoolchildren Aged 6-12 Years: Reference Values of the Battery EUROFIT and Associated Cardiovascular Risk», Journal of School Health, 84(10), 625-635.

LiRIA, R. (2012): «Consecuencias de la obesidad en el niño y el adolescente: un problema que requiere atención», Revista Peruana de Medicina Experimental y Salud Pública, 29(3), 357-360.

Maravé, M., Zorrilla, L., i J. Gil (2016): «Aprendizaje por proyectos». En: O. Chiva i Martí, M. (eds.), Métodos pedagógicos activos y globalizadores. Conceptualización y propuestas de aplicación, Barcelona, Graó, p. 123-137.

Moliner-Urdiales, D., Ruiz, J. R., Vicente-Rodriguez, G., Ortega, F. i altres (2011): «Associations of muscular and cardiorespiratory fitness with total and central body fat in adolescents: the HELENA study», British Journal of Sports Medicine, 45(2), 101-108.

Ortega, F.B., Cadenas-Sánchez, C., G. Sánchez-Delgado, i altres (2015). «Systematic Review and Proposal of a Field-Based Physical Fitness-Test Battery in Preschool Children: The PREFIT Battery», Sports Medicine, 45(4), 533-555. 
Ortega, F.B., Ruiz, J.R., M.J. Castillo, i altres (2008): «Physical fitness in childhood and adolescence: a powerful marker of health», International Journal of Obesity, 32(1), 1-11.

Ortega, F. B., Tresaco, B., Ruiz, J. R., L.A. Moreno i altres (2007): «Cardiorespiratory Fitness and Sedentary Activities Are Associated with Adiposity in Adolescents», Obesity, 15(6), 1589-1599.

Rey-López, J.P., Vicente-Rodríguez, G., Biosca, M. i L.A. Moreno (2008): «Sedentary behaviour and obesity development in children and adolescents», Nutrition, Metabolism, and Cardiovascular Diseases, 18(3), 242-251

Ruiz, J., CAstro-Pinero, J., E. Artero i altres (2009): Predictive validity of health-related fitness in youth: a systematic review. British Journal of Sports Medicine, 43(12), 909-923.

Ruiz, J., CAstro-Piñero, J. i V. EsPaña-Romero i altres (2011): Field-based fitness assessment in young people: the ALPHA health-related fitness test battery for children and adolescents. British Journal of Sports Medicine, 45(6), 518-24.

Ruiz, J., Ortega, F., WÄrnberG, J., L. Moreno i altres (2008): «Inflammatory proteins and muscle strength in adolescents: the Avena study», Archives of Pediatrics \& Adolescent Medicine, 162(5), 462-468.

Ruiz, J. (2011): El cuento motor en la educación infantil y en la educación física escolar: cómo construir un espacio para jugar, cooperar, convivir y crear, Sevilla, Wanceulen.

TAYlor, H., Buskirk, E., i A. Henschel (1955): «Maximal oxygen intake as an objective measure of cardio-respiratory performance», Journal of Applied Physiology, 8(1), 73-80.

Tucker, P. (2008): «The physical activity levels of preschool-aged children: A systematic review», Early Childhood Research Quarterly, 23(4), 547-558.

Ward, D., Vaughn, A., McWilliams, C. i D. Hales (2010): «Interventions for Increasing Physical Activity at Child Care», Medicine \& Science in Sports \& Exercise, 42(3), 526-534.

\section{BIONOTES}

\section{Diego Moliner Urdiales}

Doctor en Ciències de l'Activitat Física i l'Esport per la Universitat de Saragossa. Llicenciat en Ciències de l'Activitat Física i l'Esport per l'INEFC-Lleida. Màster en Alt Rendiment Esportiu COE-UAM. Professor del Departament d'Educació de l'UJI. Coordinador del Grup d'investigació LIFE Physical Activity, Fitness and Health de l'UJI.

\section{Óscar Chiva Bartoll}

Doctor interuniversitari amb menció internacional per la Universitat Jaume I i la Universitat de València. Llicenciat en Ciències de l'Activitat Física i l'Esport per la Universitat de València. Màster en Investigació i Intervenció en CCAFD. Màster en Ėtica i Democràcia. Postgrau d'especialització en Gestió Esportiva. Professor del Departament d'Educació de l'UJI.

\section{María Reyes Beltrán Valls}

Doctora amb menció europea en Aspectes Biomèdics de l'Activitat Física i la Salut per la Universitat de Roma Fòrum Itàlic. Llicenciada en Ciències de l'Activitat Física i l'Esport per l'INEFC-Lleida. Màster Europeu en Activitat Física i Salut. Professora del grau en Ciències de l'Activitat Física i l'Esport en EUSES-TE, centre adscrit a la URV. Investigadora postdoctoral en el Grup d'investigació LIFE Physical Activity, Fitness and Health de l'UJI. 